\title{
Problems and opportunities in the use of technology to manage informal learning
}

\author{
Francisco José García-Peñalvo \\ GRIAL Research Group, \\ Research Institute for Educational Sciences, University of Salamanca, Spain \\ fgarcia@usal.es \\ David Griffiths, Mark Johnson, Paul Sharples, David Sherlock \\ Institute for Educational Cybernetics, University of Bolton, UK \\ \{D.E.griffiths, M.W.Johnson, P.Sharples, D.Sherlock\}@bolton.ac.uk
}

\begin{abstract}
There is a mismatch between the enthusiasm of policy makers and other actors for initiatives to support the validation of informal learning, and the lack of adoption of systems in practice. This problem is explored, with reference to the creation of the Informal Learning Collector in the European Commission TRAILER project. It is proposed that formality in learning can be usefully understood as a measure of the degree of managerial control over the learning process. It is then argued that the use of managerial tools, such as validation and competence catalogues, runs the danger of constraining the scope for informal learning. Analytics techniques offer the possibility of providing insight into practice by examining documents, without the need for formal description or tagging. However, these methods raise problems of surveillance (by companies and the state), confidentiality, and security of data. A prototype system is described which tests the feasibility of the approach.
\end{abstract}

\section{Categories and Subject Descriptors}

D.1.2 [User/Machine Systems], H.3.5 [Online Information Services], H5.2 [User Interfaces], H.5.4 [Hypertext/Hypermedia], K.3.1 [Computer Uses in Education]

\section{General Terms}

Informal Learning, Human Factors.

\section{Keywords}

Informal Learning; Learning Analytics; Human-Computer Interaction.

\section{INTRODUCTION}

Informal learning is an increasingly important element in various fields, thus enhancing informal learning practices in formal contexts (informalisation of formal learning) as somehow recognising the knowledge, competencies and skills acquired informally (formalisation of informal learning). On the one hand, the University is incorporating into their teaching methodologies informal aspects heavily influenced by the philosophy of social collaboration through online platforms. Moreover, in the professional sector, continuous training of employees in the workplace is favoured if the informal learning flows, which undoubtedly occur in the daily life of each worker, as well as interactions among peers and colleagues from other organizations, may be recognised and leveraged. Finally, agencies and policy-maker institutions, such as the European Union for example, advocate the recognition of informal learning and classify these processes as one of the major challenges for the immediate future.

As Werquin, formerly Senior Economist, OECD, affirmed in 2008: 'non-formal and informal learning visible seems to be at the forefront of a lot of public policy in the European Union and the OECD countries' [27].

The European Commission funded TRAILER project [10; 12] had a special emphasis on promoting reflection on the individual's evidences of informal learning, this way every person, through a set of workflows and a tool-based support, could make visible these evidences, tagging them and associating them with a set of competences contained in a established catalogue. When an institution has access to the informal learning evidences of all its employees, the organization is able to make decisions and acknowledge the value of their informal learning activities. Through this process of making visible the informal learning by individuals and institutional recognition, TRAILER creates a bridge for communication and a win-win process between the institution and its staff. This approach, a priori, is easy to convey to the management levels and those that are responsible for the knowledge management, the intellectual capital and human resources of the institutions. However, as evidenced after the pilot TRAILER ecosystem [11] in real situations [25], this approach, although a frontal rejection of the system is not perceived, nor the importance of informal learning in the professional development of the individual and therefore the strategy corporate knowledge management, a major barrier is observed when introducing such solutions in the day-to-day professional activities. In fact, it shows that using a proposal based on a catalogue of competences makes very difficult the ultimate goal of the process, due to the validation of informal learning becomes an extension of the management processes of the formal educational processes. 
Informal learning representation is not an easy issue and it involves several problems. In this paper we reflect on the work carried out on the TRAILER project to fulfil this mission, and consider its successes and failures, and the implications of these results. Finally we propose an alternative approach to the technological support for informal learning.

This paper is divided into three main sections. Firstly we set out the problem addressed, by examining the difficulty which has been experienced in achieving widespread adoption of systems for the validation of informal learning, and discussing the case of the TRAILER Informal Learning Collector. We then move on to consider an alternative approach to the management of informal learning, based on the use of analytics techniques and a focus on patterns of attention rather than validation. Finally we describe a system which we have built to test if this approach is feasible, and report on our conclusions.

\section{PROBLEMS WITH THE REPRESENTATION OF INFORMAL LEARNING}

\subsection{The motivation for representing informal learning}

The concern that the education offered in formal educational environments is too constrained goes back at least to Dewey's emphasis on experiential learning in the 1930s, for example in Experience and Education [7]. Since around the turn of the millennium, however, there has been a particularly intense concern about the consequences for the professional success of individuals and the economic health of societies which may result from a lack of attention to informal learning. This led to the publication of a number of influential reports on the topic, with ambitious policy objectives. These included The Learning Revolution in the UK [6], a series of publications from the Organisation for Economic Cooperation and Development, for example Werquin [28], and the European Commission, whose Council Recommendation of 20th December 2012 declared: "The validation of learning outcomes, namely knowledge, skills and competences acquired through non-formal and informal learning can play an important role in enhancing employability and mobility, as well as increasing motivation for lifelong learning, particularly in the case of the socio-economically disadvantaged or the low-qualified" [24].

\subsection{Representing informal learning in the TRAILER project}

The authors have been working on the TRAILER project, whose rationale may be stated, as follows. There are many affirmations that the majority of learning is non-formal or informal, for example Cofer [3], who states that $70 \%$ of workplace learning is informal. If this is true, then decisions made in employing and deploying workers may be unreliable, because their true skills cannot be represented to managers. If employees were provided support in reflecting on and represent their informal learning, and were able relate that learning to the needs of employers, then there would be benefits both for both parties. To achieve this methods and technological support were provided, both to validate informal learning, and also to relate the validated learning to other, more formal, learning processes. The project methodology and technology are described in detail in [9] and a summary of project achievements is available in [10; 12].

Prior to implementation of TRAILER the project carried out a survey. The respondents were drawn from the contacts of the project partners, and so are representative of potential pilot participants, rather than constituting a representative sample of the sector as a whole, see [4]. We note here three points:

- Employees do not experience barriers to their informal learning (of 147 employees $89 \%$ considered their informal learning satisfactory or very satisfactory, and $82 \%$ assessed that they had enough information and tools to locate materials and resources for learning).

- Most businesses state that informal learning is valuable (62\% of the 60 businesses surveyed)

- Even those businesses that value informal learning do not validate it ( $80 \%$ of businesses surveyed carried out no validation).

These results suggest that the project proposal fits well with the realities of business, and the experience of the TRAILER team is that a simple but effective pitch can be made to the management levels and those that are responsible for the knowledge management, the intellectual capital and human resources of the institutions: informal learning is important to employees and your business, so a system is needed to factor this into decision making.

The TRAILER system provides this functionality through an Informal Learning Collector [13]. This presupposes that the user is acting within an environment which contains a number of different tools, such as Wikipedia, YouTube, various games, social networks, forums, etc. When the learner, identifies that they have learnt something in the course of their activities they make use of the Informal Learning Collector to save a reference to the resource which they have made use of, and to tag it with competences selected from a predefined catalogue. A portfolio can be built up from these claims for informal learning, which can be filtered by the learner, and published to an institution. The institution can then make use of this information in its human resources and personnel development functions, and to facilitate dialogue.

After a detailed analysis of trials [25], some broad results may be summarised here. The usability of the system was problematic, but nevertheless the system was not rejected by users. However, significant difficulties were experienced in promoting the adoption of the approach in day-to-day professional activities. In particular the use of a catalogue of competences was seen to be a major barrier. In summary, our results confirm Werquin's judgement [27] that systems for the recognition of non-formal and informal learning "despite being rather convincing in theory, seem to have trouble taking off and reaching cruising speed". Werquin's response was to encourage a more pragmatic approach, and TRAILER sought to provide this by integrating systems with the applications which already formed part of 
the users working environment. Nevertheless the problem of adoption persists, and does so despite years of reports, funding and projects. Perhaps the time has come to ask if, despite being rather convincing, our understanding of the idea is in fact flawed.

\subsection{The identification of informal learning}

There are many definitions of informal learning [8], but one of the most succinct is that proposed by the CEDEFOP, the European Centre for the Development of Education and Training. An OECD report [19] provides a report of these, together with a number of other definitions.

- $\quad$ Formal learning: Planned and intentional learning activities

- $\quad$ Non-formal learning: Planned and intentional activities, no learning objective

- Informal learning: Not planned and non-intentional learning activities

These are coherent and useful distinctions. However, identification of the degree of formality is confused by three factors.

Firstly, the criteria for planning and intention are not always clear. For example in the Meno [20], Socrates conducts a virtuoso improvised dialogue in order to lead Meno into a state where he doubts what he knows. This is clearly informal in that it is conducted without planning while sitting under a tree. However is very much formal in its use of logic. In contrast, medieval education was highly formal, with the main activity being the study of set texts. Nevertheless this activity did not have the learning activities, objectives and assessments which we would now expect to see in formal education.

Secondly, formality is associated with modes of expression and presentation (as in 'formal use of language'), which are unrelated to planning.

Thirdly, formality is associated with knowledge. However, possible categories of cognitive activity do not map well onto popular perceptions of formality. For example knowledge of the extensive nested classifications of heavy metal music may well not be perceived as being as formal as knowledge of a set of botanical families.

For these reasons perception of formality is not as clear-cut as might be imagined from the definitions in the literature. It is therefore worth emphasising that for our purposes formality does not distinguish approaches to learning, nor the formal characteristics of the knowledge acquired. We also find it helpful to focus on the degree to which the whole learning process is shaped by management methods rather than on the planning of learning activities. In addition to helping to cut through some aspects of the three confusing factors identified above, a focus on management also makes the topic more amenable to a cybernetic analysis of education, for which [2] offers a possible model.

\section{A PROPOSED APPROACH TO REPRESENTING INFORMAL LEARNING}

\subsection{An alternative perspective on informal learning}

We have set out in the previous section that in discussing formal, non-formal, and informal learning we are not making a distinction about types of learning, but rather about the presence or absence of a management process. Seen in this way, the drive to recognise informal learning may be seen from a different perspective. In [14] it was argued the historic role of educational managers has been to determine curricula and the assessment framework, and, to some extent, the materials to be studied. They received back results and reports, but much of the detail of learners and teachers work in the course of the educational process was invisible to them. This was an inevitable consequence of the extremely high variety of learners and teachers interactions, and the limited ability of managers ability to monitor. Technology (in terms of both computing and management methods) has amplified the monitoring capability of managers, and has enabled them to manage processes which were hitherto left to the initiative of teachers and learners.

Technology (in terms of both computing and management methods) has amplified the capability of managers, and has enabled them to manage processes which were hitherto left to the initiative of teachers and learners. This increased capability of educational management has in some quarters generated support for long-standing calls for a more open educational process, which would be situated in the learners particular context and is not constrained by administrative procedures. We can affirm that this was the motivation for at least some of the researchers who worked on TRAILER. From this perspective competence based learning is an attempt to ensure that learning is not an empty administrative process, but rather enables learners to do specific things which are relevant to their personal and professional development. Similarly validation of informal learning ensures that individuals are not only assessed on their formal qualifications, but also given credit for the whole range of learning which they have achieved in their lives. Seen in this way, it appears that any well intentioned person would want to make use of both competence based learning and recognition of informal learning. Unfortunately, despite this seemingly coherent programme, our experience of TRAILER and other projects is that enthusiasm for representing informal learning is lacking.

The attentive reader will have noted that there is an obvious flaw in the motivation we have just offered for competence based learning and recognition of informal learning. Whatever the intentions of their designers may be, competence based systems and systems for the validation of informal learning both inevitably extend the reach of educational management into areas to which it did not previously have access. Any attempt to use these systems to loosen the constraints of administrative procedures, or to focus more strongly on the learners' context is consequently akin to making use of petrol to put out a fire. Like petrol, these systems may have valuable uses, but they do not 
include fighting the extension of management control of education. This analysis suggests that a high priority in supporting informal learning should be the avoidance of additional management processes.

If our analysis is correct, one is forced to ask why it is not obvious to all concerned. We would suggest two reasons.

Firstly, as argued in [14] educationalists are habituated to contradiction between incompatible explanations of the learning process. Curriculum, learning materials, teacher interventions, assessment regimes, parental influence, and social environment all make competing claims for being the determining factor in learning. Moreover, as Luhmann suggests, the whole project of applying standard educational processes in order to cultivate the individual has at its heart an irresolvable contingency (see [21] for an introduction in English). Within this context a tolerance for the idea that additional formal descriptions can lead to a more open educational process becomes more understandable.

Secondly, the contradiction disappears to the extent that one believes that informal learning has special characteristics which enable it to retain a unique character even after it has been formalised by means of competence structures or validation. While, as stated above, we do not share this belief, it may go some way to explaining continuing enthusiasm for the validation of informal learning.

\subsection{Relevant technological developments}

The validation of informal learning is largely mediated by information technology, as is the case in TRAILER. In deploying this technology we have noted that potential users are pleased that a wider range of their accomplishments will be recognised, and on the other, that it is problematic to ask the individual or institution to classify informal learning with tags and/or competences. It is therefore natural to ask if technology can be used differently, in order to support informal learning in a way which does not increase the reach of educational management. Data analytics presents itself as a candidate technology. If it were possible to simply monitor people's activities and deduce their capabilities from this, then the need to validate items of informal learning might disappear. There are increasing signs that this may be possible.

Wonga, a pay-day loans company makes decisions on whether to offer a loan to a customer with in minutes rather than hours, and does so through an automated analysis of 8000 data points (www.wonga.com). Douglas Merill, Google's former chief information officer and the founder of ZestFinance states the ambition behind this approach to personal finance: "We feel like all data is credit data, we just don't know how to use it yet, ... This is the math we all learned at Google. A page was important for what was on it, but also for how good the grammar was, what the type font was, when it was created or edited. Everything" [16].

In implementing this approach ZestFinance goes beyond Wonga, in that it "takes 70,000 signals, runs them through 10 separate underwriting models, each able to consume hundreds of thousands of variables" [5].

Data analytics also claims to be able to detect users attitudes. For example, IBM markets its Customer Experience Suite and Predictive Analytics on the basis that "Interactions can occur through a multitude of channels, including discussion boards, call center case notes, telephone conversations, e-mails, blogs and social media like Twitter. Because these types of data are typically in a more candid form (vs. a formal survey, for example), they can reflect more authentically an individual's underlying or unarticulated experiences and, if mined, can reveal a rich source of Attitudinal information" [17].

Given that financial institutions are willing to make business judgements on such analyses, it seem reasonable to speculate that judgements on personal capabilities could be made using similar methods. Such information could be useful for the learner, in obtaining a perspective on what they may be capable of, on how others see them, and on what areas they could expand into. Management is offered insight into what they can feasibly ask their employees to do.

The prospect of receiving automated feedback on one's own and others' capabilities and dispositions is attractive, but is raises dystopian prospects. Analytics services of this kind are controlled by private organisations with their own agendas. Nor do governments inspire confidence, in the wake of Snowden's revelations about the data privacy [15]. An educator has a duty of care for the people they serve, and so consequently they should be cautious about the data which they hand over to Web data services.

\subsection{A possible route forward}

We have argued that the validation of informal learning meets with resistance, and can be counterproductive, because it constitutes an extension of the reach of formal education management into areas where informal learning previously had the opportunity to flourish without constraint. One of the implications of this is that the use of such systems forces the learner to participate in a game in which their actions are the basis for the decisions of others regarding their suitability for professional life. The users may reasonably decide that they do not wish to participate in such a game. We propose that this problem can be mitigated if the system is changed in order to represent attention rather than achievement. In TRAILER the ambition was to generate validated statements about informal learning which would enable employers to take better informed decisions about who to employ or deploy. Our proposed alternative approach is to assume that employers generally know which of their employees are valuable, and in which general areas, and that they can also recognise capable candidates on the basis of general qualifications and performance at interview. It is, however, much more problematic for managers to predict exactly what they might expect an employee to know about, and which fields are sufficiently close to their current practice to be possible areas for future development. Such information could be generated by systems for informal learning which explicitly do not attempt to validate or assess skills or competence, but rather measure attention to different fields of knowledge and activity, and, optionally, attitude. This would greatly reduce the stakes for participation for employees, but maintain significant benefits for both employees and employers. Such a system could help a non-technical employer to answer the questions such as: "My employee is developing the corporate 
website. What techniques are they engaging with in doing this? Are they likely to know about PLONE? What about Java portlets? Or project management?".

\section{TESTING IF THE APPROACH IS FEASIBLE}

\subsection{The functionality of the prototype}

In the final stages of the TRAILER project we developed a prototype proof-of-concept personal thematic analysis application which responded to this proposal, building on the open source ' $R$ ' statistics application [22]. The work of Leydesdorff and his collaborators, for example [26], is a rich vein of related work which has provided both inspiration for what can be achieved by automated analysis of texts, and methods which can be applied. In our prototype the user provides inputs for a personal corpus to be analysed, which may be websites which they have visited, or documents they have created (blog posts, reports, emails...). The system carries out thematic analysis on these resources, and returns a set of topics which represent where the users attention is directed. We conceive of the system as a confidential analytics tool, which enables users to make use of the power of analytics without exposing their personal data to the scrutiny of commercial providers. The Web is made use of as a public corpus to identify connections and implications, but the documents in the personal corpus themselves are not transmitted or made public.

In this way the learner can compare the thematic analysis for their own documents, and that for the Web as a whole. For example, if they have submitted a set of documents relating to post-traumatic stress, they can compare the themes which emerge from their work with those which are related to post-traumatic stress in the literature as a whole. This gives the learner material to reflect on about the areas which they might like to expand into, and also provides the employer (if they are given access) an opportunity to understand what an expert in posttraumatic stress might be expected to know about. It is intended that this information will be a basis for discussion, either informally, or as part of a Personal Development Plan.

In the Figure 1 we show how, on the left the system has performed a thematic analysis on the content at a set of web addresses linked to post-traumatic stress disorder, which the user has selected as being relevant to their current activities. On the right the user has searched the Web for similar results and can compare them. The search can be recursive, that is to say the user can choose to take any of the results and perform a new analysis on that term. If users want to further refine the topics, they can select one of the topics already found, either in the topic list generated by the 'R' application, or in the related topics mined from the web as a whole. In Figure 2, we show how the results can be presented graphically, to facilitate reflection on the differences between the users personal profile and the thematic content of the Web as a whole.

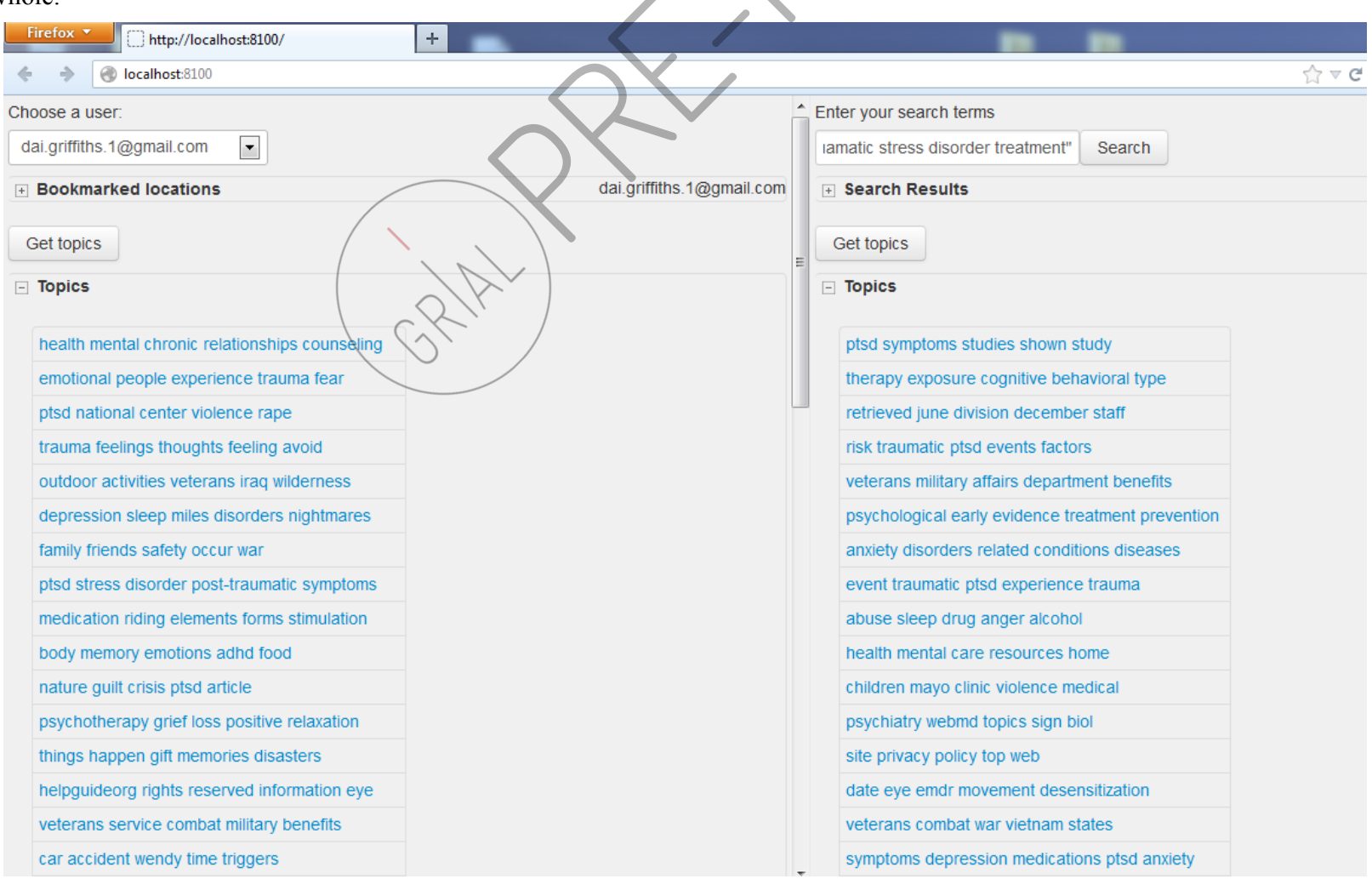

Figure 1. Thematic analysis on the content (left side) and web searching of the similar terms (right side) in order to compare the results. 


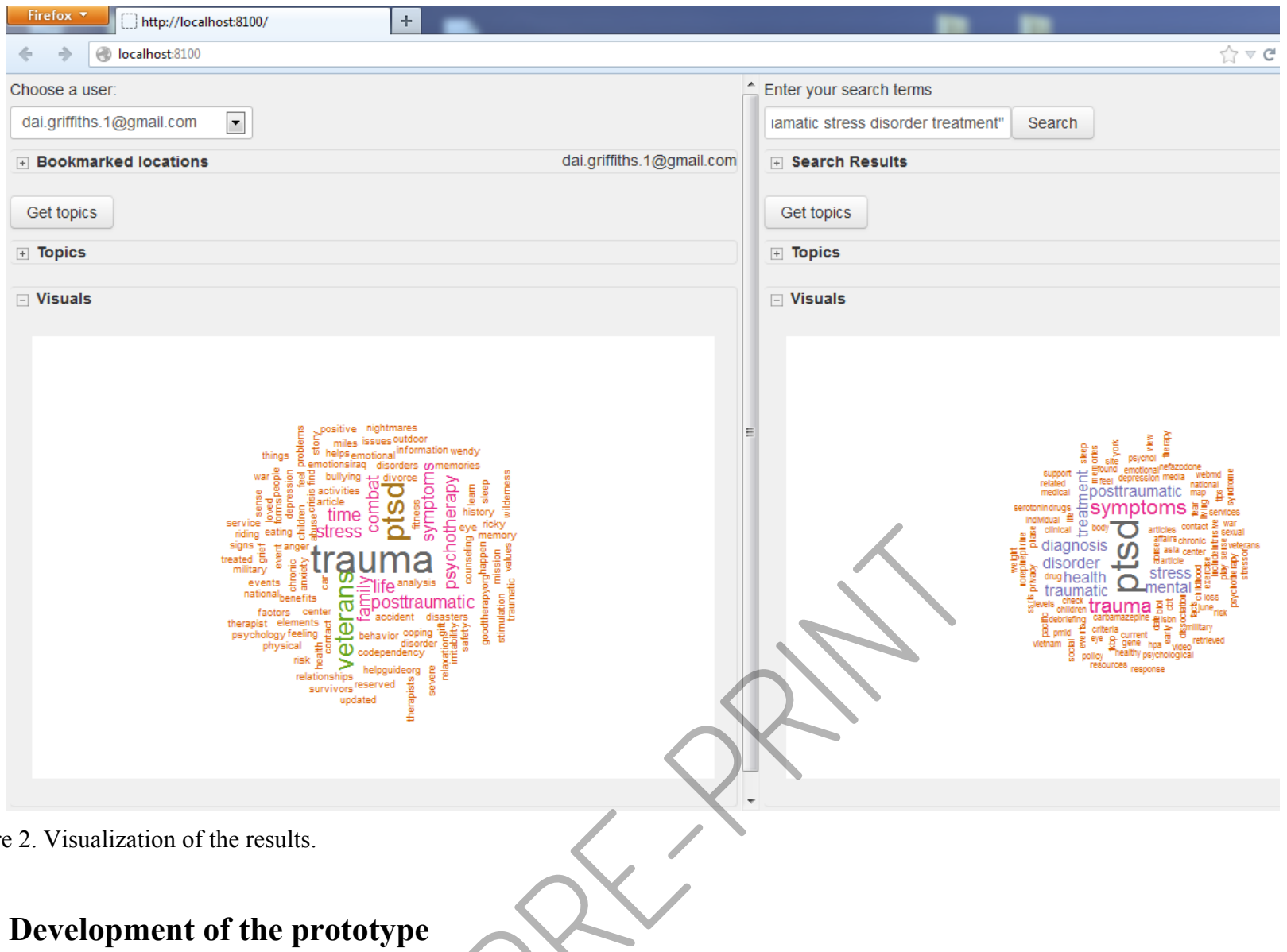

\subsection{Development of the prototype}

The 'R' statistics language and environment was chosen due to its extensibility, allowing users to include statistical methods developed by members of the community. This gives access to a range of thematic analysis methods that could be dropped in or out of the tool. The prototype served two purposes; firstly it allowed the developers to quickly experiment with different thematic analysis methods. Secondly it made it possible for users of the tool to import the same implementation of a method into their own 'R' based environment if they wanted access to the techniques in a private space. In the context of unified management processes and tools for managing non-formal and informal learning it might appear counter-intuitive to give the option of preventing access to the source data. However, it has the key advantage of offering users the possibility of choosing to whom they expose their documents, and to avoid submitting confidential information documents to third party Web services. The result is a low stakes system as far as employees or students are concerned, capable of providing results which indicate patterns of attention, without providing information which can be used for assessment of achievement.

The input to the prototype for analysis was a personal corpus, which was gathered by creating a portfolio belonging to a particular user, gathered from the TRAILER Informal Learning Collector. This portfolio was comprised of a set of web bookmarks, or URLs and contained links to various types of resources such as static web pages, dynamic web page (on which the content will change over a period of time), as well as other document formats such as Word and PDF documents found on the Internet. The prototype analysed the bookmarks by use of web scraping, in that each bookmarked resource was parsed for text. This produced a personal corpus which is a scraping of text from a list of resources that have been tagged as useful by a user and gives an insight into the attention of the user (to the extent that the user has tagged it as being a document that they have engaged with in the course of their work). The thematic analysis itself was implemented using a method described as probabilistic topic modelling [1] and was used with the Personal Corpus information. The analysis used an implementation of the algorithm as implemented by the Mallet toolkit [18], to group words together as belonging to the same topic. To further develop the prototype beyond its initial command line interface we looked at ways to visualise the prototype and allow user interaction. In order to realise this we implemented an interactive user interface using the recently developed Shiny $\mathrm{R}$ package [23] which allows developers to build rich user interfaces making use of standard HTML and CSS components, while also allowing native $\mathrm{R}$ functions to render to the screen, such as charts, graphs and word clouds.

The prototype currently feeds back the topics and a visual representation that shows the frequency in which terms occur in topics using a word cloud, but a wide range of representations could be developed. This well-known visual representation gives users an 'at a glance' view of popular keywords across things in which their attention is directed. The words shown are those identified as topics that the 
algorithm has identified, and higher the frequency of these topics found in the personal corpus, the more prominently they appear in the word cloud.

\subsection{Improvements to the prototype}

In its first version the prototype took its portfolio of bookmarks from the Informal Learning Collector. This meant that only information which had been captured in that environment could be used as input. This also meant that the prototype could not be made openly available because it contained user specific portfolio information gathered during the course of the project. With this in mind, a second iteration was developed which removed reliance on the Informal Learning Collector and instead used existing bookmarking and tagging software available on the web. The second version of the prototype makes use of the Delicious (https://delicious.com) web service. Users now are able to enter a delicious user account in the Shiny web application, which will in turn interrogate bookmarks and tags located there. There is also scope to add additional service providers for the portfolio data.

\subsection{Issues and challenges}

The visual elements of the tool give an indication of how many times a word is used across topics but not how popular those topics are across the personal corpus. For example a word that does not appear often in the text, but is associated with many topics will be big in the visual representation. The probabilistic slant of topic modelling means that the algorithms often need 'fine tuning' depending on factors such as the length of documents, number of documents. Fine tuning the algorithm is often a case of trial and error, looking at results and changing the inputs manually. While this may be fine for a user running the $\mathrm{R}$ environment who has the ability to tweak the settings, it is harder for an organization wanting to use such tools without the need for an underlying understanding of how the tool-sets work. This is one area which could be improved, with the addition of some form of advanced parsing technique which could allow end users to be able to manipulate how and what exactly is included into the Personal Corpus.

Other challenges relate to the fact that data on the Web is often not static. For example users who marked a BBC page as useful received different topics depending on the time that the page was analysed, this was because widgets on the page would display the latest popular news. Obviously, if someone was to use the prototype to examine dynamic content of this type it may or may not yield results which are different from those generated on the date and time when the resource was originally tagged and bookmarked. Additionally, problems also arise when users bookmark content which requires authentication or authorisation to view it, as without the credentials the prototype cannot access it. The ability to easily store a copy of a page, rather than to simply bookmark it, could be investigated in this regard.

\section{CONCLUSIONS AND FURTHER WORK}

The purpose of the implementation work reported above was to test if it was feasible to implement an approach to the representation of informal learning which focused on attention, and which leveraged analytics while maintaining confidentiality. The results show that this approach is indeed feasible, and offers a possible alternative to the well-established approach of validating informal learning, often making use of competency structures. This is a worthwhile result, because it indicates a possible route out of the impasse presented by the lack of adoption of systems for representing and validating formal learning. However, the work is at an early stage, and we plan to deepen our work in two directions. Firstly we intend to expand our investigation of what is possible with these techniques, which are rapidly increasing in power. Secondly, we will carry out research to establish if use of the system in practice provides evidence in favour of our critique of established methods of managing informal learning. This work will require a focused programme of research, and work with a substantial number of users, both from industry and higher education (including both students and lecturers).

The prototype confidential analytics tool could be enhanced by including a much more sophisticated web scraping and parsing engine. The aim would be to enhance the parsing of complex content, such as embedded content and aggregated content - where the content viewed on screen is in fact a combination of several different component parts from different locations on the web. Additionally it is envisaged that the future tool could be separated out into an engine component detached from any user interface. The engine component would then be able to plug in to a traditional web application, such as the Shiny implementation used in the prototype, but also more interestingly it could be used locally within a desktop application that anyone could download and install. In the present implementation this requires the user to install the whole of the 'R' package. An easy to install desktop version would make it much simpler to combine collection of web content with analysis of private files on a users personal machine, which, as we have discussed above, allows users to leverage the analytical tools while keeping original content to themselves. For the approach which we have adopted it will be essential that users find it not only possible, but easy to establish their own analytics process on their own machine, and that the boundaries between personal and public domains of analysis is entirely clear. This will give users confidence in analysing confidential documents, and avoiding the implication that the user's capability is being tested, rather than their patterns of attention.

\section{REFERENCES}

[1] BLEI, D.M., 2012. Probabilistic topic models. Communications of the ACM 55, 4, 77-84.

[2] BRITAIN, S., LIBER, O., and FROM, R.T.J., 2004. A Framework for the Pedagogical Evaluation of eLearning Environments. Jisc Cetis.

[3] COFER, D.A., 2000. Informal Workplace Learning. Centre on Education and Training for Employment, Ohio State University.

[4] CONDE-GONZÁLEZ, M.Á., GARCÍA-PEÑALVO, F.J., ZANGRANDO, V., GARCÍA-HOLGADO, A., SEOANE-PARDO, A.M., ALIER, M., GALANIS, N., GRIFFITHS, D., JOHNSON, M., JANSSEN, J., BROUNS, F., VOGTEN, H., FINDERS, A., SLOEP, P., MARQUES, M.A., VIEGAS, M.C., ALVES, G., WASZKIEWICZ, E., MYKOWSKA, A., MINOVIC, M., and MILOVANOVIC, M., 2013. Enhancing informal learning recognition through TRAILER project. In Proceedings of the Workshop on 
Solutions that Enhance Informal Learning Recognition (WEILER 2013). Co-located with 8th European Conference on Technology Enhanced Learning (EC-TEL 2013) (Paphos, Cyprus, September 18, 2013), F.J. GARCÍA-PEÑALVO, M.A. CONDE-GONZÁLEZ and D. GRIFFITHS Eds. CEUR Workshop Proceedings, 21-30.

[5] CROSSMAN, P., 2012. ZestFinance Aims to Fix Underwriting for the Underbanked. In American Banker.

[6] DEPARTMENT FOR INNOVATION, UNIVERSITIES AND SKILLS, 2009. The Learning Revolution.

[7] DEWEY, J., 1938. Experience \& Education. Kappa Delta Pi, New York, NY.

[8] GARCÍA-PEÑALVO, F.J., COLOMO-PALACIOS, R., and LYTRAS, M.D., 2012. Informal learning in work environments: training with the Social Web in the workplace. Behaviour \& Information Technology 31, 8, 753-755. DOI= http://dx.doi.org/10.1080/0144929x.2012.661548.

[9] GARCÍA-PEÑALVO, F.J., CONDE, M.Á., JOHNSON, M., and ALIER, M., 2013. Knowledge Co-Creation Process Based on Informal Learning Competences Tagging and Recognition. International Journal of Human Capital and Information Technology Professionals (IJHCITP) 4, 4, 18-30. DOI= http://dx.doi.org/10.4018/ijhcitp.2013100102.

[10] GARCÍA-PEÑALVO, F.J., CONDE, M.Á., ZANGRANDO, V., GARCÍA-HOLGADO, A., SEOANE, A.M., ALIER, M., GALANIS, N., BROUNS, F., VOGTEN, H., GRIFFITHS, D., MYKOWSKA, A., RIBEIRO-ALVES, G., and MINOVIĆ, M., 2013. TRAILER Project (Tagging, Recognition, Acknowledgment of Informal Learning Experiences). A Methodology to Make Learners' Informal Learning Activities Visible to the Institutions. Journal of Universal Computer Science 19, 11, 1661-1683.

[11] GARCÍA-PEÑALVO, F.J., JOHNSON, M., RIBEIRO ALVES, G., and MINOVIC, M., 2014. Informal learning recognition through a cloud ecosystem. Future Generation Computer Systems 32, $282-294 . \quad$ DOI= http://dx.doi.org/http://dx.doi.org/10.1016/j.future.2013.08.004.

[12] GARCÍA-PEÑALVO, F.J., ZANGRANDO, V., GARCÍA-HOLGADO, A., CONDE, M.Á., SEONE PARDO, A.M., ALIER FORMENT, M., JANSSEN, J., GRIFFITHS, D., MYKOWSKA, A., RIBEIRO ALVES, G., and MINOVIC, M., 2012. TRAILER project overview: Tagging, recognition and acknowledgment of informal learning experiences. In Proceedings of the 2012 International Symposium on Computers in Education (SIIE) (Andorra La Vella, Andorra. October 29-31, 20122012), Institute of Electrical and Electronics Engineers.

[13] GARCÍA-PEÑALVO, F.J., ZANGRANDO, V., GARCÍA-HOLGADO, A., CONDE-GONZÁLEZ, M.Á., SEOANE-PARDO, A.M., ALIER, M., GALANIS, N., LÓPEZ, J., JANSSEN, J., BROUNS, F., FINDERS, A., BERLANGA, A., SLOEP, P., GRIFFITHS, D., JOHNSON, M., WASZKIEWICZ, E., MYKOWSKA, A., MINOVIC, M., MILOVANOVIC, M., MARQUES, M.A., VIEGAS, M.C., and ALVES, G., 2013. A Tool to Aid Institutions Recognize Their Employees Competences Acquired by Informal Learning. In Scaling up Learning for Sustained Impact. 8th European Conference onTechnology Enhanced Learning,EC-TEL2013. Paphos, Cyprus, September 17-21, 2013 Proceedings (Paphos, Cyprus, September 17-21, 2013), D. HERNÁNDEZ-LEO, T. LEY, R. KLAMMA and A. HARRER Eds. Springer Verlag, Berlin, Heidelberg, 552-555. DOI= http://dx.doi.org/10.1007/978-3-642-40814456.

[14] GRIFFITHS, D., 2013. The educational consequences of Bateson's economy of flexibility. Kybernetes 42, 9/10, 1387-1395. DOI= http://dx.doi.org/http://dx.doi.org/10.1108/K-10-2012-0075.

[15] GUARDIAN, T., 2013. The NSA Files. In The Guardian.

[16] HARDY, Q., 2012. Just the Facts. Yes, All of Them. In New York Times.

[17] IBM SOFTWARE GROUP, 2013. IBM Customer Experience Suite and Predictive Analytics.

[18] MALLET, 2013. MAchine Learning for LanguagE Toolkit (Mallet).

[19] OECD, 2007. Terms Concepts and Models for Analysing the Value of Recognition Programmes. Organisation for Economic Cooperation and Development.

[20] PLATO, 2008. Meno. Gutenberg Project.

[21] QVORTRUP, L., 2005. Society's Educational System - An introduction to Niklas Luhmann's pedagogical theory. Seminar.net International journal of media, technology and lifelong learning 1, 1, 1-21.

[22] R CORE TEAM, 2013. R: A language and environment for statistical computing R Foundation for Statistical Computing, Vienna, Austria.

[23] SHINY, 2014. Easy web applications in R.

[24] THE COUNCIL OF THE EUROPEAN UNION, 2012. COUNCIL RECOMMENDATION of 20 December 2012 on the validation of non-formal and informal learning. European Union.

[25] VIEGAS, C., MARQUES, M., ALVES, G., MYKOWSKA, A., GALANIS, N., ALIER, M., BROUNS, F., JANSSEN, J., GARCÍAPEÑALVO, F.J., GARCÍA-HOLGADO, A., ZANGRANDO, V., and CONDE-GONZÁLEZ, M.A., 2014. TRAILER - a Tool for Managing Informal Learning. International Journal of Human Capital and Information Technology Professionals (IJHCITP) In Press.

[26] VLIEGER, E. and LEYDESDORFF, L., 2011. Content Analysis and the Measurement of Meaning: The Visualization of Frames in Collections of Messages. The Public Journal of Semiotics 3, 1, 28-50.

[27] WERQUIN, P., 2008. Recognition of non-formal and informal learning in OECD countries:A very good idea in jeopardy? Lifelong Learning in Europe 2008, 3, 42-49.

[28] WERQUIN, P., 2010. Recognising Non-Formal and Informal Learning: Outcomes, Policies and Practices. Organisation for Economic Co-operation and Development. 